\title{
10-Year Trends in Dietary Intakes in the High- and Low-Risk Areas for Esophageal Cancer: A Population-Based Ecological Study in Northern Iran
}

\author{
Faezeh Salamat ${ }^{1}$, Shahryar Semnani ${ }^{1,2}$, Mohammad Reza Honarvar ${ }^{3}$, Abdolreza Fazel ${ }^{4}$, Gholamreza Roshandel ${ }^{1, *}$
}

1. Golestan Research Center of Gastroenterology and Hepatology, Golestan University of Medical Sciences, Gorgan, Iran

2. Omid Cancer Research Center, Omid Preventive Medicine and Health Promotion Center, Golestan University of Medical Sciences, Gorgan, Iran

3. Health Management and Social Development Research Center, Golestan University of Medical Sciences, Gorgan, Iran

4. Cancer Research Center, Golestan University of Medical Sciences, Gorgan, Iran

\footnotetext{
* Corresponding Author:
}

Gholamreza Roshandel, MD, PhD Golestan Research Center of Gastroenterology and Hepatology, Sayyad Shirazi Hospital, Sayyad Shirazi Boulevard, Gorgan, Iran Tel: + 981732251910 Fax: + 981732451657 Email: roshandel_md@yahoo.com

Received: 01 Dec. 2019 Accepted: 10 Mar. 2020

\section{ABSTRACT}

\section{BACKGROUND}

We assessed dietary intakes in the high- and low-risk areas for esophageal cancer (EC) in Golestan province, Northern Iran.

\section{METHODS}

Considering the EC rates, Golestan province was divided into high- and low-risk regions. Data on households' food consumption were obtained from the Statistical Center of Iran. We used multivariable logistic regression to assess the relationships between consumption of main food and EC risk. Adjusted odds ratios (aOR) were calculated. Joint point program was used for time trend analysis and average annual percent changes (AAPC) were reported.

\section{RESULTS}

Overall, 11910 households were recruited during 2006-2015. 4710 (39.5\%) households were enrolled from the high-risk region. There were significant positive relationships between high consumption of sweets ( $\mathrm{aOR}=1.62 ; 95 \% \mathrm{CI}: 1.24-2.10)$, oil/fat $(\mathrm{aOR}=1.36 ; 95 \% \mathrm{CI}: 1.04-1.79)$, and red meat $(\mathrm{aOR}=1.33 ; 95 \% \mathrm{CI}: 1.07-1.65)$ with $\mathrm{EC}$ risk. We found significant negative relationships between high consumption of dairy products $(\mathrm{aOR}=0.62 ; 95 \% \mathrm{CI}: 0.46-0.82)$, vegetables $(\mathrm{aOR}=0.66 ; 95 \% \mathrm{CI}$ : $0.50-0.87)$ and fruit ( $\mathrm{aOR}=0.72 ; 95 \% \mathrm{CI}: 0.55-0.95)$ with the risk of $\mathrm{EC}$. Time trend analysis showed a significant increasing trend in the proportions of households with low consumption of vegetables $(\mathrm{AAPC}=4.71, p=0.01)$ and dairy products $(\mathrm{AAPC}=5.26, p=0.02)$ in the low-risk region for $\mathrm{EC}$.

\section{CONCLUSION}

Dietary intakes may be important etiological factors for EC in Northern Iran. Further studies are warranted to assess the role of dietary factors in this high-risk population.

\section{KEYWORDS:}

Diet, Esophageal cancer, Vegetables and Fruit, Ecological study

\section{Please cite this paper as:}

Salamat F, Semnani S, Honarvar MR, Fazel AR, Roshandel GR. 10-Year Trends in Dietary Intakes in the High- and Low-Risk Areas for Esophageal Cancer: A PopulationBased Ecological Study in Northern Iran. Middle East J Dig Dis 2020;12:89-98. doi: 10.34172/mejdd.2020.167.

\section{INTRODUCTION}

Esophageal cancer (EC) is the 11 th most common cancer $(3.2 \%$ of all incident cancers) and the 8 th most common cause of cancer death $(5.3 \%$ of all cancer deaths) worldwide. Most of the EC incidence and mortality occur in developing countries.

There are diversities in the incidence rates of EC between different countries 
as well as different parts of each country. A very high incidence rate of EC was reported from the northeast of Iran. ${ }^{2,3}$ Several reports from this region showed a significant relationship between $\mathrm{EC}$ and some risk factors such as low socioeconomic status, ${ }^{4}$ opium consumption, smoking, alcohol consumption, ${ }^{5}$ poor oral hygiene, ${ }^{6}$ drinking hot tea, ${ }^{7}$ exposure to inappropriate polycyclic aromatic hydrocarbons (PAH), ${ }^{8}$ and dietary intakes. ${ }^{9,10}$ The association between EC and dietary intakes were investigated in different studies in Northern Iran. Cook-Mozaffari and colleagues reported strong associations between low socioeconomic status and low intake of fresh fruit and vegetables with the risk of EC. ${ }^{11}$

High consumption of vegetables, fruits, cereals, and tea had a protective association with the risk of EC. But, frequent consumptions of meat, animal fats, and salt were mildly associated with increased risk. ${ }^{12}$ In another study on EC, Eduardo De Stefani and co-workers reported a clear protective effect for consumption of fruits and vegetables. They also reported an increased risk with daily consumption of barbecued meat. ${ }^{13,14}$ Hormozdiari and others found a low intake of vitamins $\mathrm{A}$ and $\mathrm{C}$, riboflavin, animal protein, fresh vegetables. and fruit as well as high consumption of sheep's and goat's milk in a high-risk area for EC. ${ }^{15}$

Golestan province in Northern Iran has been known as a high-risk region for EC since 1970s. ${ }^{3}$ Recent studies showed different incidence rates for EC in different sub-divisions of Golestan province. ${ }^{16,17}$ Accordingly, we divided the province into high and low-risk regions for EC. ${ }^{18}$ Some studies showed differences in the levels of some risk factors between the two regions. ${ }^{18-20}$ Investigation of dietary intakes, as an important risk factor for EC, may produce helpful evidence in identifying the etiologic factors for EC in this population. The aim of this study was to compare the consumption of main foods between high and low-risk regions for EC of Golestan province during 2006-2015.

\section{MATERIALS AND METHODS}

This was a population-based ecological study. It was conducted in Golestan province, Northern Iran. Considering previously described methods and based on the incidence rates of $\mathrm{EC}$, we divided the province into high (Turkmensahra) and low-risk areas for EC. ${ }^{16-18}$
We collected household food consumption data from the Household Income and Expenditure Survey (HIES) of the Statistical Center of Iran (SCI) during 2006 and 2015. ${ }^{21}$ The methodological issues of the HIES including sample size calculation and sampling methods were designed according to the Standard Protocols of the National Household Survey Capability Program (NHSCP), ${ }^{22}$ and System of National Accounts (SNA) ${ }^{23}$ Briefly, using a multi-stage stratified sampling method, 387250 households were recruited in HIES during 2006-2015. At the main national level, each province was considered as a stratum. The sample size (number of households) of each stratum was calculated using a proportional to size method. In each province, villages (in rural areas) and city blocks (in urban areas) were identified as provincial-level strata. Finally, a simple randomization method (using household code) was considered to select the study units (households) according to the previously identified sample size in each stratum.

The present study was designed in Golestan province. Regarding the findings of the HIES project in previous years (unpublished data), the proportions of households with high consumption of sweet, oil and fat, and red meat in high versus low-risk areas of Golestan province were $40 \%$ versus $32 \%, 37 \%$ versus $27 \%$, and $36 \%$ versus $30 \%$, respectively. The results of previous HIES projects in this region also suggested that the proportions of low consumption of vegetables, fruits, dairy products, spices, and grain/beans in low versus high-risk areas were 31\% versus $37 \%$, 33\% versus $39 \%$, 29\% versus $34 \%, 39 \%$ versus $30 \%$, and $30 \%$ versus $27 \%$, respectively. Considering a confidence level of 0.95 and a study power of $80 \%$, the highest sample size was calculated for grain/bean $(7108$ households). Considering a design effect of 1.5 and a response rate of about $90 \%$ (based on the results of a previous survey), the final sample size of this study was calculated as 11500 households.

The process of data collection in HIES was done using a standard questionnaire. The questionnaire was developed according to the United Nations (UN) recommendations and considering the National Household Survey Capability Program (NHSCP) ${ }^{22}$ and SNA publications. ${ }^{23}$ It consisted of two main parts including income and expenditure, and the section of expenditure was further categorized into dietary and non-dietary parts. The 
dietary section of HIES questionnaire included information about the amount of foods (in gram) consumed by households during the last month. ${ }^{24}$ Time of interview (in each year) and the structure of the questionnaire were not changed during the study period.

For the present study, amounts (in gram) of households' consumption of nine commonly used major food groups including red meats, fish, dairy products, oils, fruits, vegetables, cereals and legumes, sweet, and spices during 2006-2015 were extracted from the HIES dataset and entered into the analysis. Considering the tertile distribution of food consumption, households were categorized into three groups including the 1 st tertile (low consumption), the 2 nd tertile (intermediate consumption), and the $3 \mathrm{rd}$ tertile (high consumption). We calculated the proportions of households in each group of food consumption.

The proportions of households in the subgroups of food consumption were compared between the low and high-risk areas for EC. Crude odds ratios and 95\% confidence intervals (CI) were calculated. Multivariable logistic regression analysis was performed to assess the strongest variables (food groups) related to the risk of EC. Variables with $\mathrm{P}$ values less than 0.2 in univariable analysis were entered into the multivariable model. Adjusted odds ratio (aOR) and 95\% CI were calculated. Regarding the possible differences in dietary intakes between rural and urban areas, households' place of residence was also entered into the analysis. Finally, the results were adjusted for the place of residence as well as for selected food groups including red fruits, vegetables, meats, fish, dairy products, oils, cereals and legumes, sweet, and spices.

We also performed a time trend analysis using a Joint point software version 4.0.4. ${ }^{25}$ The proportions of households with low consumption of vegetables, fruits, and dairy products as well as those with high consumption of sweets, oil and fat, and red meats were entered into the trend analysis. Assuming a Poisson distribution, the average annual percent changes (AAPCs) in proportions were calculated by generalized linear models. A weighted least-square regression was performed, considering the year and the neutral logarithm of proportions as independent and dependent variables, respectively. Finally, 95\% CI of AAPCs was calculated using heteroscedastic errors. The trend was considered as significant if 95\% CI of AAPC did not include zero. $p$ values of less than 0.05 were considered significant. Ethical issues of this project were reviewed and approved by the Ethics Committee of Golestan University of Medical Sciences.

\section{RESULTS}

In total, 11910 households were recruited in this study. $4710(39.5 \%)$ households were selected from high-risk region for EC and 5680 (47.7\%) households were recruited from cities (table 1).

The proportions of households with high consumption of red meat $(34.1 \%$ vs $31.5 \%)$, oil and fat $(36.0 \%$ vs $31.9 \%$ ), sweets $(37.5 \%$ vs $30.3 \%)$, fish $(30.2 \%$ vs $24.7 \%$ ), grain and bean (35.9\% vs $31.7 \%$ ), and spices (34.3\% vs 30.5\%) were higher in high risk region compared with low risk region (table 1).

Households from high risk region showed lower consumption of vegetable $(28.4 \%$ vs $36.3 \%)$, fruits (31.5\% vs $34.3 \%)$, and dairy products ( $29.2 \%$ vs $35.2 \%)$ compared with those from low risk region (table 1 ).

Results of multivariable logistic regression suggested significant positive relationships between high consumption of sweets $(\mathrm{aOR}=1.62 ; 95 \% \mathrm{CI}: 1.24-2.10)$, oil and fat $(\mathrm{aOR}=1.36 ; 95 \% \mathrm{CI}: 1.04-1.79)$, and red meat $(\mathrm{aOR}=1.33 ; 95 \% \mathrm{CI}: 1.07-1.65)$ with the risk of EC (table 2). Our findings also showed significant negative relationships between high consumption of vegetables $(\mathrm{aOR}=0.66 ; 95 \% \mathrm{CI}: 0.50-0.87)$, fruits $(\mathrm{aOR}=0.72$; $95 \%$ CI: $0.55-0.95)$, and dairy products $(\mathrm{aOR}=0.62$; 95\% CI: 0.46-0.82) with the risk of EC (table 2).

The results of trend analysis showed a significant increasing trend in proportions of households with low consumption of vegetables $(\mathrm{AAPC}=4.71 ; p=0.01)$ and dairy products $(\mathrm{AAPC}=5.26 ; p=0.02)$ in the low-risk region (figure 1). There was a significant decrease in the proportion of households with high consumption of sweets both in high-risk (AAPC $=-1.79 ; p=0.02$ ) and low-risk regions (AAPC $=-6.03 ; p<0.01$ ) (figure 2). Similar decreasing trends were also found in oil and fat consumption but the trend was significant only in highrisk region ( $\mathrm{AAPC}=-2.98 ; p=0.01$ ) (figure 2). There was no significant change in fruits (figure 1) and red meats (figure 2 ) consumption during the study period.

\section{DISCUSSION}

Our findings suggested a significant inverse relationship 
Table 1: Numbers and proportions (\%) of households with low, intermediate, and high consumption of foods in low and high risk regions for esophageal squamous cell carcinoma in Golestan province, Iran, 2006-2015

\begin{tabular}{|c|c|c|c|c|c|c|}
\hline & & \multicolumn{2}{|c|}{ Low risk region } & \multicolumn{2}{|c|}{ High risk region } & \multirow{2}{*}{ Total } \\
\hline & & $\mathrm{N}^{*}$ & $\%$ & $\mathbf{N}^{*}$ & $\%$ & \\
\hline \multirow{2}{*}{ Place of residence } & Urban & 3565 & 49.5 & 2115 & 44.9 & 5680 \\
\hline & Rural & 3635 & 50.5 & 2595 & 55.1 & 6230 \\
\hline \multirow{3}{*}{ Red meat } & Low & 1883 & 50.6 & 1078 & 47.9 & 2961 \\
\hline & Intermediate & 666 & 17.9 & 406 & 18.4 & 1072 \\
\hline & High & 1173 & 31.5 & 767 & 34.1 & 1940 \\
\hline \multirow{3}{*}{ Oil and fat } & Low & 2054 & 30.9 & 1128 & 25.8 & 3182 \\
\hline & Intermediate & 2473 & 37.2 & 1672 & 38.2 & 4145 \\
\hline & High & 2117 & 31.9 & 1575 & 36.0 & 3692 \\
\hline \multirow{3}{*}{ Vegetables } & Low & 2361 & 33.1 & 1771 & 38.0 & 4132 \\
\hline & Intermediate & 2177 & 30.5 & 1568 & 33.6 & 3745 \\
\hline & High & 2589 & 36.3 & 1322 & 28.4 & 3911 \\
\hline \multirow{3}{*}{ Fruits } & Low & 2530 & 35.4 & 1703 & 36.4 & 4233 \\
\hline & Intermediate & 2166 & 30.3 & 1501 & 32.1 & 3667 \\
\hline & High & 2457 & 34.3 & 1475 & 31.5 & 3932 \\
\hline \multirow{3}{*}{ Sweets } & Low & 2425 & 36.4 & 1300 & 29.1 & 3725 \\
\hline & Intermediate & 2212 & 33.2 & 1488 & 33.3 & 3700 \\
\hline & High & 2017 & 30.3 & 1674 & 37.5 & 3691 \\
\hline \multirow{3}{*}{ Fish } & Low & 2195 & 45.4 & 1712 & 40.0 & 3907 \\
\hline & Intermediate & 2328 & 29.9 & 1501 & 29.7 & 3829 \\
\hline & High & 2456 & 24.7 & 1325 & 30.2 & 3781 \\
\hline \multirow{3}{*}{ Dairy Products } & Low & 2195 & 31.4 & 1712 & 37.7 & 3907 \\
\hline & Intermediate & 2328 & 33.4 & 1501 & 33.1 & 3829 \\
\hline & High & 2456 & 35.2 & 1325 & 29.2 & 3781 \\
\hline \multirow{3}{*}{ Grain and bean } & Low & 2453 & 35.0 & 1466 & 31.9 & 3919 \\
\hline & Intermediate & 2330 & 33.3 & 1476 & 32.2 & 3806 \\
\hline & High & 2221 & 31.7 & 1648 & 35.9 & 3869 \\
\hline \multirow{3}{*}{ Spices } & Low & 2361 & 37.0 & 1227 & 28.1 & 3588 \\
\hline & Intermediate & 2067 & 32.4 & 1636 & 37.5 & 3703 \\
\hline & High & 1947 & 30.5 & 1497 & 34.3 & 3444 \\
\hline
\end{tabular}

*Missing values were excluded

between vegetable and fruit consumption with the risk of EC. Higher consumption of fruit and vegetables was associated with significant decreases in the risks of different malignancies including malignancies of the esophagus, lung, stomach, and colorectal. ${ }^{26-28}$ According to the previous reports from different populations, higher consumption 
Table 2: Multivariable logistic regression analysis for assessing the relationship between dietary intakes with the risk of esophageal squamous cell carcinoma in Golestan province of Iran

\begin{tabular}{|c|c|c|c|c|c|c|c|c|c|}
\hline & & \multicolumn{4}{|c|}{ Univariate analysis } & \multicolumn{4}{|c|}{ Multivariable analysis* } \\
\hline & & $\begin{array}{c}\text { Crude } \\
\text { OR }\end{array}$ & & & $p$ & $\begin{array}{l}\text { Adjusted } \\
\text { OR }\end{array}$ & & & $p$ \\
\hline \multirow{2}{*}{ Place of residence } & Urban & - & - & - & - & - & - & - & - \\
\hline & Rural & 1.20 & 1.12 & 1.30 & $<0.001$ & 1.05 & 0.86 & 1.28 & 0.629 \\
\hline \multirow{3}{*}{ Red meat } & Low & - & - & - & - & - & - & - & - \\
\hline & Intermediate & 1.06 & 0.92 & 1.23 & 0.394 & 1.44 & 1.12 & 1.85 & 0.004 \\
\hline & High & 1.14 & 1.02 & 1.29 & 0.027 & 1.33 & 1.07 & 1.65 & 0.010 \\
\hline \multirow{3}{*}{ Oil and fat } & Low & - & - & - & - & - & - & - & - \\
\hline & Intermediate & 1.23 & 1.12 & 1.35 & $<0.001$ & 1.08 & 0.84 & 1.39 & 0.560 \\
\hline & High & 1.35 & 1.23 & 1.49 & $<0.001$ & 1.36 & 1.04 & 1.79 & 0.027 \\
\hline \multirow{3}{*}{ Vegetables } & Low & - & - & - & - & - & - & - & - \\
\hline & Intermediate & 0.96 & 0.88 & 1.05 & 0.374 & 0.92 & 0.71 & 1.20 & 0.562 \\
\hline & High & 0.68 & 0.62 & 0.75 & $<0.001$ & 0.66 & 0.50 & 0.87 & 0.003 \\
\hline \multirow{3}{*}{ Fruits } & Low & - & - & - & - & - & - & - & - \\
\hline & Intermediate & 1.03 & 0.94 & 1.13 & 0.527 & 0.94 & 0.72 & 1.22 & 0.639 \\
\hline & High & 0.89 & 0.82 & 0.97 & 0.012 & 0.72 & 0.55 & 0.95 & 0.019 \\
\hline \multirow{3}{*}{ Sweets } & Low & - & - & - & - & - & - & - & - \\
\hline & Intermediate & 1.25 & 1.14 & 1.38 & $<0.001$ & 1.22 & 0.96 & 1.57 & 0.111 \\
\hline & High & 1.55 & 1.41 & 1.70 & $<0.001$ & 1.62 & 1.24 & 2.10 & $<0.001$ \\
\hline \multirow{3}{*}{ Fish } & Low & - & - & - & - & - & - & - & - \\
\hline & Intermediate & 1.13 & 0.97 & 1.32 & 0.121 & 1.21 & 0.97 & 1.51 & 0.085 \\
\hline & High & 1.39 & 1.19 & 1.63 & $<0.001$ & 1.15 & 0.91 & 1.46 & 0.229 \\
\hline \multirow{3}{*}{ Dairy products } & Low & - & - & - & - & - & - & - & - \\
\hline & Intermediate & 0.83 & 0.76 & 0.91 & $<0.001$ & 1.02 & 0.78 & 1.35 & 0.868 \\
\hline & High & 0.69 & 0.63 & 0.76 & $<0.001$ & 0.62 & 0.46 & 0.82 & 0.001 \\
\hline \multirow{3}{*}{ Grain and bean } & Low & - & - & - & - & - & - & - & - \\
\hline & Intermediate & 1.06 & 0.97 & 1.16 & 0.214 & 0.97 & 0.77 & 1.22 & 0.812 \\
\hline & High & 1.24 & 1.13 & 1.36 & $<0.001$ & 1.18 & 0.92 & 1.51 & 0.184 \\
\hline \multirow{3}{*}{ Spices } & Low & - & - & - & - & - & - & - & - \\
\hline & Intermediate & 1.52 & 1.39 & 1.67 & $<0.001$ & 1.24 & 0.98 & 1.51 & 0.092 \\
\hline & High & 1.48 & 1.34 & 1.63 & $<0.001$ & 1.21 & 0.95 & 1.55 & 0.128 \\
\hline
\end{tabular}

*The results were adjusted for place of residence as well as for selected food groups including red meats, fish, dairy products, oils, fruits, vegetables, cereals and legumes, sweet, and spices.

of fruit and vegetables may decrease the risk of EC.1 $1^{3,29-33}$ Fruits and vegetables are the main sources of antioxidants, phytoestrogens, and flavonoids especially flavanones, which can prevent the development of cancer by anti-in- 

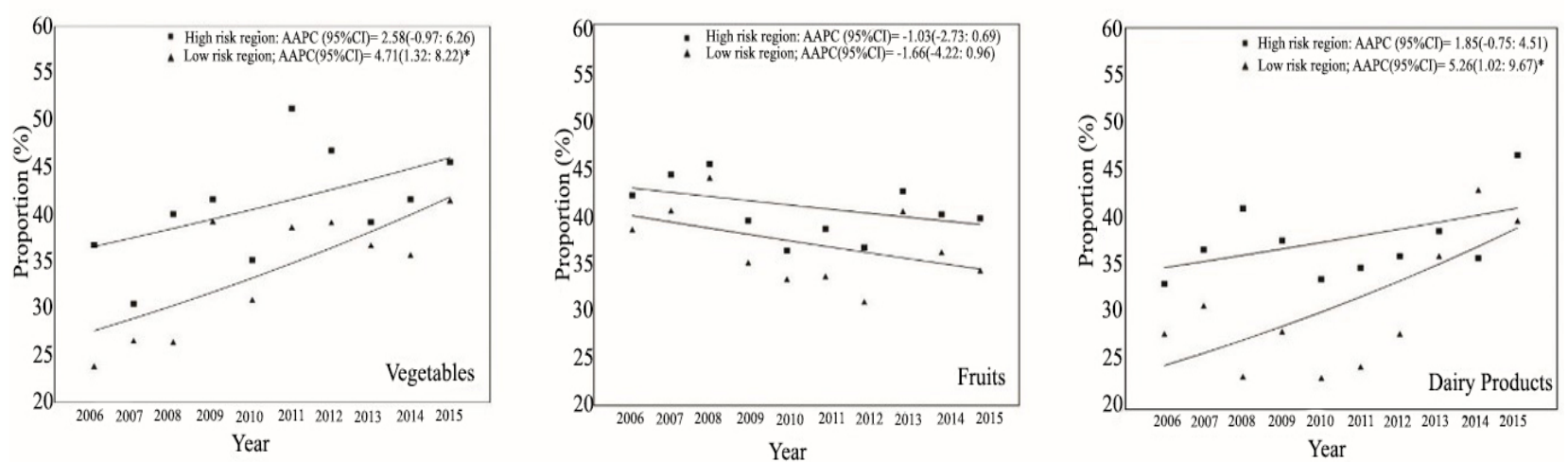

Fig.1: Proportions (\%) of households with low consumption of vegetables, fruits, and dairy products in high- and low-risk regions for EC of Golestan province, Iran, 2006-2015. (AAPC indicates average annual percent change; * indicates that AAPC is significantly different from zero at alpha $=0.05$; Dots indicate observed values; Solid lines indicate fitted lines; EC indicates esophageal cancer)
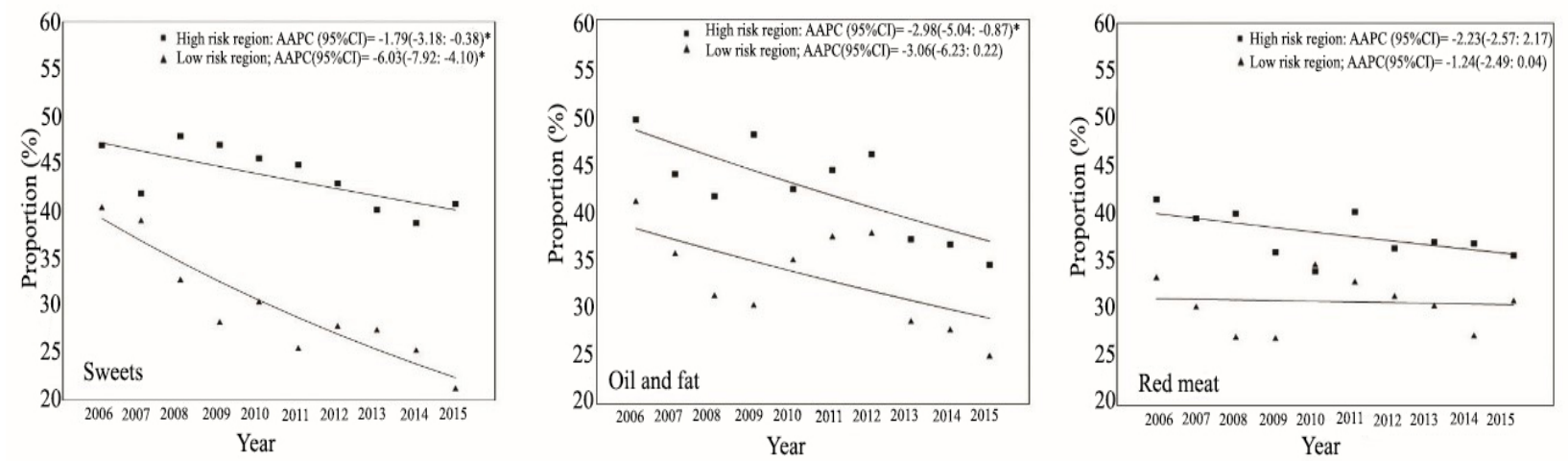

Fig.2: Proportions (\%) of households with high consumption of sweets, oil and fat, and red meat in high- and low-risk regions for EC of Golestan province, Iran, 2006-2015. (AAPC indicates average annual percent change; * indicates that AAPC is significantly different from zero at alpha $=0.05$; Dots indicate observed values; Solid lines indicate fitted lines; EC indicates esophageal cancer)

flammatory effects, free-radical scavenging, or blocking the formation of N-nitroso compounds. Other components of these foods including fiber, folate, vitamin C, vitamin A, and beta-carotene equivalents may also have anti-cancer effects. ${ }^{34-36}$

Our results also showed an increase in the proportion of households with low vegetable consumption. The trend was statistically significant in low EC risk area. Therefore, considering the relationship between low consumption of vegetables and fruits and EC as well as the decreasing trend in vegetable consumption, a priority in health policy making especially for cancer controlling programs in this population should be considered. Appropriate interventions should be designed and implemented to increase vegetables and fruits consumption in both high and low-risk regions for EC of Golestan province.

We found a significant positive relationship between high red meat consumption and EC risk. Other studies also showed that high red meat consumption may be related to increased risk of EC..$^{14,34,35,37-42}$ The carcinogenic effects of red meat may be due to its compounds including $\mathrm{N}$-nitroso compounds, heterocyclic amines (HCA), or polycyclic aromatic hydrocarbons (PAH). Heme iron that is seen especially in high amounts in red meat causes the formation of N-nitroso compounds. ${ }^{42,43}$ When muscle meat, such as beef is cooked using high-temperature cooking methods for example in pan-frying or grilling directly over an open flame or smoking of meats, HCAs and PAHs are formed. ${ }^{44}$ These compounds may increase DNA synthesis and cell proliferation, affect hormone metabolism, increase insulin-like growth factors, promote free radical damage, and produce carcinogenic heterocyclic amines, all of which may progress into the development of cancer. ${ }^{41}$ The results of a recent study from Northern Iran, 
showed a considerable dose-response relationship between $\mathrm{PAH}$ and risk of EC, suggesting a causal role for exposure to PAH in the pathogenesis of EC. ${ }^{45} \mathrm{HCAs}$ and PAHs may cause changes in DNA by specific enzymes in the body, the "bioactivation" process that may increase the risk of cancer. Diversities in the activity of these enzymes in different individuals may be related to the risk of developing cancers in those exposed to HCAs and PAHs. ${ }^{46-48}$ Interventions reducing red meat consumption will decrease exposure to these carcinogenic compounds. Therefore, red meat consumption reducing interventions may be considered as an important activity in EC controlling program. Our results showed no significant change in the proportion of households with high red meat consumption in Golestan province during 2006-2015. Therefore, reducing red meat consumption may be noted as a priority in health policy making in our population as well as other high-risk regions.

Our findings showed that households in the high-risk region had significantly higher consumption of oil and fat. The relationship between high fat consumption and different cancers including colorectal cancers ${ }^{49}$ and EC 34,50-52 were suggested in previous studies. High consumption of oil and fat have been known as risk factors for EC, and controlling this risk factor will result in reducing the burden of EC in high-risk populations. The observed decreasing trend in oil and fat consumption in our population (figure 2) may possibly be occurred due to the implementation of oil and fat reducing policies during the last decade in Iran. But, despite this decreasing trend, the proportion of households with high consumption of oil and fat remained higher in high-risk regions. So, additional and more effective interventions are needed in this high-risk region.

Households in the high-risk region for EC showed significantly higher consumption of sweets. High intake of sweet foods was associated with different cancers including colorectal cancer, ${ }^{49}$ breast cancer, ${ }^{53}$ and pancreatic cancer. ${ }^{54}$ High sweet consumption may increase the glycemic index (GI) and glycemic load (GL). Increasing in GI is often associated with obesity and underlies the increased risk of EC. ${ }^{55}$ The increase in GI and GL may also change the regulation of insulin-like growth factors and apoptosis in cancer cells in the esophagus, resulting in a higher risk of EC. ${ }^{56}$ We also found a significant decreasing trend in the consumption of sweet foods in our population, most probably resulted from the implementation of administrative policies and educational programs. But, the AAPC was considerably lower (-1.79) in high risk than low risk (-6.03) regions, suggesting the need for more serious interventions in high-risk regions.

Our results suggested a significantly lower consumption of dairy products in the high-risk area. Previous studies also showed inverse relationships between consumption of dairy products and the risk of different cancers including colorectal, ${ }^{57}$ breast, ${ }^{58,59}$ and EC. ${ }^{13,38}$ The results of a recent study from Golestan province suggested a negative association between dairy product intake and all-cause mortality as well as cardiovascular mortality. The findings did not show a significant relationship between dairy product intake and cancer mortality. ${ }^{60}$ Further investigations should be conducted to clarify this point in our population.

In this study, we considered an ecological design and data collection was performed at the household level. Therefore, the issue of ecological fallacy should be considered in the interpretation of the results especially for findings with discrepancies with the results of previous studies. In addition, we have used previously collected data from the HIES project and we did not have access to information regarding the response rate and therefore, we could not adjust the results for selection bias due to non-response. Lack of data on types of fats (saturated, monounsaturated, trans, and polyunsaturated) was another limitation of this study.

The relationship between fat consumption and the risk of EC may depend on the types of fat. Therefore, this point should be notified in future studies. These limitations should be mentioned in the interpretation of our findings. However, our findings were in line with the results of previous individual-level studies on different populations. Therefore, the results of the present study may be useful in designing EC controlling programs.

In conclusion, we found a significant inverse relationship between EC risk and consumption of vegetables, fruits, and dairy products. Our results also suggested significant positive relationships between meat, sweet, and oil and fat consumption with the risk of EC. We also found an increase in the proportions of households with low consumption of vegetables and dairy products, and the trends were statistically significant in low-risk regions. Dietary intakes may be considered as important etiological factors for EC in Northern Iran. Therefore, further individual-level studies 
are warranted to clarify the role of dietary factors on the risk of EC in this high-risk population.

\section{ACKNOWLEDGMENTS}

This work was supported by Golestan Research Center of Gastroenterology and Hepatology, Golestan University of Medical Sciences (grant number: 64754). The authors would like to thank the Statistical Center of Iran for providing the data of the household income and expenditure survey (HIES).

\section{Funding statements:}

This work was supported by the Golestan Research Center of Gastroenterology and Hepatology, Golestan University of Medical Sciences (grant number: 64754).

\section{ETHICAL APPROVAL}

There is nothing to be declared.

\section{CONFLICT OF INTEREST}

The authors declare no conflict of interest related to this work.

\section{REFERENCES}

1. Bray F, Ferlay J, Soerjomataram I, Siegel RL, Torre LA, Jemal A. Global cancer statistics 2018: GLOBOCAN estimates of incidence and mortality worldwide for 36 cancers in 185 countries. CA Cancer J Clin 2018;68: 394424. doi: $10.3322 /$ caac. 21492 .

2. Bird-Lieberman EL, Fitzgerald RC. Early diagnosis of oesophageal cancer. Br J Cancer 2009;7;101:1-6. doi: 10.1038/sj.bjc.6605126.

3. Kmet J, Mahboubi E. Esophageal cancer in the Caspian littoral of Iran: initial studies. Science 1972;175: 846-53. doi: 10.1126/science. 175.4024 .846

4. Islami F, Kamangar F, Nasrollahzadeh D, Aghcheli K, Sotoudeh M, Abedi-Ardekani B, et al. Socio-economic status and oesophageal cancer: results from a populationbased case-control study in a high-risk area. Int J Epidemiol 2009;38:978-88. doi: 10.1093/ije/dyp195.

5. Nasrollahzadeh D, Kamangar F, Aghcheli K, Sotoudeh $\mathrm{M}$, Islami F, Abnet CC, et al. Opium, tobacco, and alcohol use in relation to oesophageal squamous cell carcinoma in a high-risk area of Iran. Br J Cancer 2008;98:1857-63. doi: $10.1038 /$ sj.bjc. 6604369 .

6. Sepehr A, Kamangar F, Fahimi S, Saidi F, Abnet CC, Dawsey SM. Poor oral health as a risk factor for esophageal squamous dysplasia in northeastern Iran. Anticancer Res 2005;25: 543-6.
7. Islami F, Pourshams A, Nasrollahzadeh D, Kamangar F, Fahimi S, Shakeri R, et al. Tea drinking habits and oesophageal cancer in a high risk area in northern Iran: population based case-control study. BMJ 2009;338: b929. doi: 10.1136/bmj.b929.

8. Roshandel G, Semnani S, Malekzadeh R, Dawsey SM. Polycyclic aromatic hydrocarbons and esophageal squamous cell carcinoma. Arch Iran Med 2012;15:713-22. doi: 0121511/AIM.0013.

9. Hashemian M, Murphy G, Etemadi A, Poustchi $H$, Sharafkhah M, Kamangar F, et al. Nut consumption and the risk of oesophageal squamous cell carcinoma in the Golestan Cohort Study. Br J Cancer 2018;119: 176-81. doi: 10.1038/s41416-018-0148-0.

10. Hashemian M, Poustchi H, Abnet CC, Boffetta P, Dawsey SM, Brennan PJ, et al. Dietary intake of minerals and risk of esophageal squamous cell carcinoma: results from the Golestan Cohort Study. Am J Clin Nutr 2015;102:102-8. doi: 10.3945/ajen.115.107847.

11. Cook-Mozaffari PJ, Azordegan F, Day NE, Ressicaud A, Sabai C, Aramesh B. Oesophageal cancer studies in the Caspian Littoral of Iran: results of a case-control study. Br J Cancer 1979;39:293-309. doi: 10.1038/bjc.1979.54.

12. Castellsague X, Munoz N, De Stefani E, Victora CG, Castelletto R, Rolon PA. Influence of mate drinking, hot beverages and diet on esophageal cancer risk in South America. Int $J$ Cancer 2000;88:65864. doi: 10.1002/1097-0215(20001115)88:4<658::aidijc22>3.0.co;2-t.

13. Fan Y, Yuan JM, Wang R, Gao YT, Yu MC. Alcohol, tobacco, and diet in relation to esophageal cancer: the Shanghai Cohort Study. Nutr Cancer 2008;60:354-63. doi: 10.1080/01635580701883011.

14. De Stefani E, Deneo-Pellegrini H, Ronco AL, Boffetta P, Correa P, Aune D, et al. Meat consumption, cooking methods, mutagens, and risk of squamous cell carcinoma of the esophagus: a case-control study in Uruguay. Nutr Cancer 2012;64:294-9. doi: 10.1080/01635581.2012.648299.

15. Hormozdiari H, Day NE, Aramesh B, Mahboubi E. Dietary factors and esophageal cancer in the Caspian Littoral of Iran. Cancer Res 1975; 35: 3493-8.

16. Roshandel G, Sadjadi A, Aarabi M, Keshtkar A, Sedaghat SM, Nouraie SM, et al. Cancer incidence in Golestan Province: report of an ongoing population-based cancer registry in Iran between 2004 and 2008. Arch Iran Med 2012;15:196-200. doi: 012154/AIM.004.

17. Roshandel G, Semnani S, Fazel A, Honarvar M, Taziki $\mathrm{M}$, Sedaghat $\mathrm{S}$, et al. Building cancer registries in a lower resource setting: The 10-year experience of Golestan, Northern Iran. Cancer Epidemiol 2018; 52: 128-33. doi: 10.1016/j.canep.2017.12.014.

18. Semnani S, Roshandel G, Zendehbad A, Keshtkar A, Rahimzadeh H, Abdolahi N, et al. Soils selenium level and esophageal cancer: an ecological study in a high risk area for esophageal cancer. J Trace Elem Med Biol 2010;24:174-7. doi: 10.1016/j.jtemb.2010.03.002. 
19. Rahimzadeh-Barzoki H, Joshaghani H, Beirami S, Mansurian M, Semnani S, Roshandel G. Selenium levels in rice samples from high and low risk areas for esophageal cancer. Saudi Med J 2014;35:617-20.

20. Ghasemi-Kebria F, Joshaghani H, Taheri NS, Semnani S, Aarabi M, Salamat F, et al. Aflatoxin contamination of wheat flour and the risk of esophageal cancer in a high risk area in Iran. Cancer Epidemiol 2013;37:290-3. doi: 10.1016/j.canep.2013.01.010.

21. Population and census office, editor. Household Income and Expenditure Survey. Tehran: Statistical center of Iran; 2010 .

22. United Nations, editor. National Household Survey Capability Programme, Household Income and Expenditure Surveys: A technical Study. New York: United Nationas; 1989.

23. Inter-Secretariat Working Group on National Accounts, editor. System of national accounts. New York: United Nations; 1993.

24. Salamat F, Semnani S, Aboomardani M, Roshandel G. Temporal variations of dietary habits in a high-risk area for upper gastrointestinal cancers: a population-based study from northern Iran. Asian Pac J Cancer Prev 2015;16:2537-42. doi: 10.7314/apjcp.2015.16.6.2537.

25. Statistical Research and Applications Branch, editor. Joinpoint Regression Program, Version 4.0.4. Bethesda: National Cancer Institute; 2013.

26. Feskanich D, Ziegler RG, Michaud DS, Giovannucci EL, Speizer FE, Willett WC, et al. Prospective study of fruit and vegetable consumption and risk of lung cancer among men and women. J Natl Cancer Inst 2000;92:1812-23. doi: 10.1093/jnci/92.22.1812.

27. Riboli E, Norat T. Epidemiologic evidence of the protective effect of fruit and vegetables on cancer risk. Am J Clin Nutr 2003;78:559S-69S. doi: 10.1093/ajen/78.3.559S.

28. Voorrips LE, Goldbohm RA, van Poppel G, Sturmans F, Hermus RJ, van den Brandt PA. Vegetable and fruit consumption and risks of colon and rectal cancer in a prospective cohort study: The Netherlands Cohort Study on Diet and Cancer. Am J Epidemiol 2000;152:108192. doi: 10.1093/aje/152.11.1081.

29. Rossi M, Garavello W, Talamini R, La Vecchia C, Franceschi $\mathrm{S}$, Lagiou P, et al. Flavonoids and risk of squamous cell esophageal cancer. Int J Cancer 2007;120:1560-4. doi: 10.1002/ijc.22499

30. Palladino-Davis AG, Mendez BM, Fisichella PM, Davis CS. Dietary habits and esophageal cancer. Dis Esophagus 2015;28:59-67. doi: 10.1111/dote.12097.

31. Bravi F, Edefonti V, Randi G, Garavello W, La Vecchia C, Ferraroni M, et al. Dietary patterns and the risk of esophageal cancer. Ann Oncol 2012;23:765-70. doi: 10.1093/annonc/ mdr295.

32. Li B, Jiang G, Zhang G, Xue Q, Zhang H, Wang C, et al. Intake of vegetables and fruit and risk of esophageal adenocarcinoma: a meta-analysis of observational studies.
Eur J Nutr 2014;53:1511-21. doi: 10.1007/s00394-0140656-5.

33. Tang L, Lee AH, Xu F, Zhang T, Lei J, Binns CW. Fruit and vegetable consumption and risk of esophageal cancer: a case-control study in north-west China. Dis Esophagus 2014;27:777-82. doi: 10.1111/dote.12157.

34. Navarro Silvera SA, Mayne ST, Risch H, Gammon MD, Vaughan TL, Chow WH, et al. Food group intake and risk of subtypes of esophageal and gastric cancer. Int J Cancer 2008;123:852-60. doi: 10.1002/ijc.23544.

35. De Stefani E, Deneo-Pellegrini H, Ronco AL, Boffetta $\mathrm{P}$, Brennan P, Munoz N, et al. Food groups and risk of squamous cell carcinoma of the oesophagus: a case-control study in Uruguay. Br J Cancer 2003;89:1209-14. doi: 10.1038/ sj.bjc.6601239.

36. BosettiC,LaVecchiaC, TalaminiR, SimonatoL,ZambonP, NegriE, et al. Food groups and risk of squamous cell esophageal cancer in northern Italy. Int J Cancer 2000;87:28994. doi: 10.1002/1097-0215(20000715)87:2<289::AIDIJC22>3.0.CO;2-9.

37. Salehi M, Moradi-Lakeh M, Salehi MH, Nojomi M, Kolahdooz F. Meat, fish, and esophageal cancer risk: a systematic review and dose-response meta-analysis. Nutr Rev 2013;71:257-67. doi: 10.1111/nure.12028.

38. Levi F, Pasche C, Lucchini F, Bosetti C, Franceschi S, Monnier $\mathrm{P}$, et al. Food groups and oesophageal cancer risk in Vaud, Switzerland. Eur J Cancer Prev 2000;9:25763. doi: 10.1097/00008469-200008000-00005.

39. Ibiebele TI, Hughes MC, Whiteman DC, Webb PM. Dietary patterns and risk of oesophageal cancers: a populationbased case-control study. Br J Nutr 2012;107:1207-16. doi: $10.1017 / \mathrm{S} 0007114511004247$.

40. Gonzalez CA, Jakszyn P, Pera G, Agudo A, Bingham S, Palli D, et al. Meat intake and risk of stomach and esophageal adenocarcinoma within the European Prospective Investigation Into Cancer and Nutrition (EPIC). J Natl Cancer Inst 2006;98:345-54. doi: 10.1093/jnci/djj071.

41. Genkinger JM, Koushik A. Meat consumption and cancer risk. PLoS Med 2007;4:e345. doi: 10.1371/journal. pmed.0040345.

42. Choi Y, Song S, Song Y, Lee JE. Consumption of red and processed meat and esophageal cancer risk: meta-analysis. World J Gastroenterol 2013;19:1020-9. doi: 10.3748/ wjg.v19.17.1020.

43. Zhu HC, Yang X, Xu LP, Zhao LJ, Tao GZ, Zhang C, et al. Meat consumption is associated with esophageal cancer risk in a meat- and cancer-histological-type dependent manner. Dig Dis Sci 2014;59:664-73. doi: 10.1007/s10620-013-2928-y.

44. Cross AJ, Sinha R. Meat-related mutagens/carcinogens in the etiology of colorectal cancer. Environ Mol Mutagen 2004;44:44-55. doi: 10.1002/em.20030.

45. Abedi-Ardekani B, Kamangar F, Hewitt SM, Hainaut $\mathrm{P}$, Sotoudeh M, Abnet CC, et al. Polycyclic aromatic hydrocarbon exposure in oesophageal tissue and risk 
of oesophageal squamous cell carcinoma in northeastern Iran. Gut 2010;59:1178-83. doi: 10.1136/ gut.2010.210609.

46. Moonen H, Engels L, Kleinjans J, Kok T. The CYP1A2164A-->C polymorphism (CYP1A2*1F) is associated with the risk for colorectal adenomas in humans. Cancer Lett 2005; 229: 25-31. doi: 10.1016/j.canlet.2004.12.010.

47. Butler LM, Duguay Y, Millikan RC, Sinha R, Gagne JF, Sandler RS, et al. Joint effects between UDP-glucuronosyltransferase 1A7 genotype and dietary carcinogen exposure on risk of colon cancer. Cancer Epidemiol Biomarkers Prev 2005;14:1626-32. doi: 10.1158/10559965.EPI-04-0682.

48. Lopes AB, Metzdorf M, Metzdorf L, Sousa MPR, Kavalco C, Etemadi A, et al. Urinary Concentrations of Polycyclic Aromatic Hydrocarbon Metabolites in Mate Drinkers in Rio Grande do Sul, Brazil. Cancer Epidemiol Biomarkers Prev 2018;27:331-7. doi: 10.1158/10559965.EPI-17-0773.

49. Azizi H, Asadollahi K, Davtalab Esmaeili E, Mirzapoor M. Iranian dietary patterns and risk of colorectal cancer. Health Promot Perspect 2015;5:72-80. doi: 10.15171/ hpp.2015.009.

50. Lagergren K, Lindam A, Lagergren J. Dietary proportions of carbohydrates, fat, and protein and risk of oesophageal cancer by histological type. PLoS One 2013;8: e54913. doi: 10.1371/journal.pone.0054913.

51. Jessri M, Rashidkhani B, Hajizadeh B, Jessri M, Gotay C. Macronutrients, vitamins and minerals intake and risk of esophageal squamous cell carcinoma: a case-control study in Iran. Nutr $J$ 2011;10:137. doi: 10.1186/14752891-10-137.

52. De Ceglie A, Fisher DA, Filiberti R, Blanchi S, Conio M. Barrett's esophagus, esophageal and esophagogastric junction adenocarcinomas: the role of diet. Clin Res Hepatol Gastroenterol 2011;35:7-16. doi: 10.1016/j. gcb.2010.08.015.

53. Tavani A, Giordano L, Gallus S, Talamini R, Franceschi $\mathrm{S}$, Giacosa A, et al. Consumption of sweet foods and breast cancer risk in Italy. Ann Oncol 2006;17:341-5. doi: 10.1093/annonc/mdj051.

54. Larsson SC, Bergkvist L, Wolk A. Consumption of sugar and sugar-sweetened foods and the risk of pancreatic cancer in a prospective study. Am J Clin Nutr 2006;84:1171-6. doi: 10.1093/ajen/84.5.1171.

55. Mulholland HG, Cantwell MM, Anderson LA, Johnston BT, Watson RG, Murphy SJ, et al. Glycemic index, carbohydrate and fiber intakes and risk of reflux esophagitis, Barrett's esophagus, and esophageal adenocarcinoma. Cancer Causes Control 2009;20:279-88. doi: 10.1007/ s10552-008-9242-6.

56. Eslamian G, Jessri M, Hajizadeh B, Ibiebele TI, Rashidkhani B. Higher glycemic index and glycemic load diet is associated with increased risk of esophageal squamous cell carcinoma: a case-control study. Nutr Res 2013;33:71925. doi: 10.1016/j.nutres.2013.06.002.
57. Elwood PC, Givens DI, Beswick AD, Fehily AM, Pickering JE, Gallacher J. The survival advantage of milk and dairy consumption: an overview of evidence from cohort studies of vascular diseases, diabetes and cancer. $J$ Am Coll Nutr 2008;27:723s-34s. doi: 10.1080/07315724.2008.10719750.

58. Duarte DC, Nicolau A, Teixeira JA, Rodrigues LR. The effect of bovine milk lactoferrin on human breast cancer cell lines. J Dairy Sci 2011;94:66-76. doi: 10.3168/jds.20103629 .

59. Dong JY, Zhang L, He K, Qin LQ. Dairy consumption and risk of breast cancer: a meta-analysis of prospective cohort studies. Breast Cancer Res Treat 2011;127:23-31. doi: 10.1007/s10549-011-1467-5.

60. Farvid MS, Malekshah AF, Pourshams A, Poustchi H, Sepanlou SG, Sharafkhah M, et al. Dairy Food Intake and All-Cause, Cardiovascular Disease, and Cancer Mortality: The Golestan Cohort Study. Am J Epidemiol 2017;185:697-711. doi: 10.1093/aje/kww139. 